\title{
1. DE UNA PEDAGOGÍA DE LA CLAUSURA A UNA PEDAGOGÍA DE LAS POSIBILIDADES. APRENDER Y ENSEÑAR LA AGENCIA
}

— Henry Giroux

McMaster University

— Pablo Rivera-Vargas

Universitat de Barcelona

- Pablo Neut-Aguayo

Universitat de Barcelona

\section{Introducción}

El objetivo del presente capítulo es analizar el potencial tránsito desde una pedagogía de la clausura a una pedagogía de las posibilidades en los sistemas educativos y sociales del presente. Con el foco en la Educación Superior, el presente trabajo esta dividido en tres apartados.

En el primero se analiza cómo el orden educativo neoliberal ha estructurado una pedagogía hegemónica de carácter clausurativa, es decir, que tiene como función principal naturalizar los principios sobre los que se soporta dicho orden e impedir la imaginación de un proyecto educativo y social distinto al existente. Tras este diagnóstico, se propone avanzar en la construcción de una narrativa político-pedagógica que permita enfrentar, interrumpir y transformar la clausura que intenta el discurso educativo dominante. Para ello, en el segundo apartado, se proponen dos dimensiones que permitirían, en las antípodas del modelo hegemónico, erigir una pedagogía de la posibilidad. Es decir, un tipo de educación que habilite la posibilidad de pensar y construir trayectorias biográficas y estructuras sociales distintas a las naturalizadas por el mandato neoliberal. Este desafío implica resituar 
la agencia de los actores sociales, entendidos como sujetos soberanos y públicos capaces de construir y decidir colectivamente entre diversos futuros posibles. Finalmente, en el tercer apartado, ponemos el foco en la universidad, y como una pedagogía de la posibilidad puede transformar a esta institución en un espacio de deliberación cívica, en tanto bien social y derecho público.

\section{Una pedagogía de la clausura: la naturalización del orden educativo neoliberal}

La configuración del campo educativo supone la producción y transmisión de un tipo de conocimiento específico (Bernstein, 1998). Este, al erigirse como el saber legítimo, se presenta como único, excluyente, neutral y universal. Dicho saber se instituye como «conocimiento oficial» a través de distintas operaciones de poder, las que tienen por objetivo ocultar tanto los procesos históricos a través de los cuales el conocimiento oficial obtuvo su posición de preeminencia, como los intereses particulares a los que sirve. Al respecto, dos operatorias de ocultamiento resultan centrales en la estructuración del orden educativo neoliberal:

- El saber legítimo se autoinstituye como el único posible: El conocimiento oficial se presenta como una verdad final y objetiva antes que como el resultado de la disputa entre distintos proyectos sociales y educativos. Es un tipo de conocimiento que enmascara los procesos históricos de selección que le han dado forma, presentándose como un saber que extrae la fuerza de su autoproclamada «cientificidad» y no de la imposición fáctica sobre otras alternativas político-pedagógicas. Así, el conocimiento oficial oculta los procesos sociohistóricos de lucha por la hegemonía en el campo educativo (Rivera, Neut y Neut, 2020). Esconder la trama histórica de disputa entre propuestas político-pedagógicas antagónicas permite presentar al conocimiento oficial como un tipo de saber aséptico, ahistórico y, por tanto, único y exclusivo. Es una forma de ocultamiento que naturaliza lo existente como lo único posible. 
- El saber legítimo se presenta como más limitado en su rango de acción de lo que efectivamente es: El conocimiento oficial se explicita en un conjunto de contenidos (teóricos, procedimentales y actitudinales) que involucran la dimensión «evidente» $\mathbf{o}$ «medible» de los procesos de enseñanza-aprendizaje. Estos forman el currículum explícito. En principio, el proceso formativo debería ceñirse a lo dictado por dicho currículum. Sin embargo, los procesos educativos lo superan ampliamente. En efecto, en todo proceso formativo existe un currículum oculto (Giroux, 2004) que enseña no solo contenidos sino también relaciones sociales, ideologías, narrativas de sí, de los otros y del mundo. La educación supone un proceso de imposición de significaciones que, en la medida que se oculta, produce una violencia simbólica (Bourdieu y Passeron, 1995). Así, el currículum oculto permite consolidar, de manera violenta, aunque inadvertida, un sentido común que refuerza los valores hegemónicos y el tipo de relaciones sociales predominantes. Con esta operatoria se silencia el modo en que la educación actúa como una fuerza conservadora y reproductora del orden existente.

En el contexto actual, ambas operatorias de ocultamiento se anudan para constituir un tipo de pedagogía de carácter clausurativa que naturaliza el orden educativo neoliberal. Por un lado, el ocultamiento del carácter selectivo del conocimiento oficial instala al saber neoliberal como el único existente. Su lenguaje permea a todo el sistema educativo: emprendedurismo, educación por competencias, excelencia académica, management, redes globales, innovación, etc. Por otro lado, el currículum oculto transforma las prácticas universitarias en prácticas empresariales, generando un tipo de formación instrumental a los contenidos neoliberales: fondos concursables, estandarización, productividad científica, investigación aplicada (I+D), incentivos a la productividad, etc. Finalmente, las relaciones sociales son trasvestidas como relaciones educativas: obediencia mecánica, jerarquías incuestionables, autoritarismo, etc. La educación, en consecuencia, se dirige a desarrollar la capacidad adaptativa frente a los mandatos del ordenamiento neoliberal. 
En este escenario, las operatorias de ocultamiento dificultan construir modelos y prácticas educativas con horizontes emancipatorios. Esto se debe a que aquello que está más allá del orden neoliberal «se convierte como no existente, y de hecho es producido como no existente» (De Sousa, 2010, p. 29). Esta es precisamente la esencia de la pedagogía de la clausura: no solo señala los límites de lo posible, sino que produce activamente lo imposible.

En otras palabras, el orden educativo neoliberal es naturalizado a tal grado que aquello que enfrenta sus principios no solo es visto como inviable o poco probable desde una perspectiva pragmática, sino como impensable e inexistente desde una perspectiva epistemológica y política. No es la inviabilidad práctica de otro proyecto lo que estimula la pedagogía de la clausura, sino la posibilidad misma de llegar a pensarlo.

Frente a la implacabilidad de esta pedagogía de la clausura se deben desarrollar narrativas y prácticas que permitan construir una educación que, lejos de la naturalización del presente y su perpetuación proyectiva, abran puertas para la definición de otros futuros.

\section{Una pedagogía de las posibilidades}

Una pedagogía que conteste los principios de la clausura neoliberal debe sustentarse en una premisa básica: el presente constituye el desenlace de luchas y disputas pasadas y, por tanto, el futuro constituirá el desenlace de las disputas desplegadas en el presente. Comprender de esta manera la historicidad del orden social y educativo (es decir, como el resultado contingente y abierto de la pugna entre distintos proyectos) permite reposicionar a la educación como un espacio de apertura para la construcción de otros futuros. En otras palabras, como un lugar que enseña las posibilidades de acción en -y sobre- el mundo.

Si el presente y el futuro son susceptibles de ser modificados debido a sus caracteres históricos y no inmutables, la educación tiene la misión de formar a ciudadanas y ciudadanos soberanos y públicos que decidan colectivamente su futuro. Así, la escuela y la universidad 
antes que educar en la adaptación al sistema, debería volcarse al desarrollo de la agencia. Destacamos a continuación dos dimensiones orientadas en esta dirección.

\section{Alfabetización cívica}

Una pedagogía de la posibilidad es aquella que inserta a los sujetos en las disputas actuales para que estos puedan actuar y decidir el tipo de futuro en que quieren vivir, pues, como señala Freire, «en la experiencia histórica de la cual participo, el mañana no es algo "pre-dado», sino un desafío, un problema [...]. El futuro es problemático y no inexorable» (Freire, 2012, pp. 10 y 99).

Para afrontar esta problematicidad, la alfabetización, como proceso y dispositivo político (Freire, 1985; Giroux, 2004), debe girar en torno a la construcción de narrativas que proporcionen otras formas de imaginación y de actuación sobre el futuro. En concreto, la alfabetización cívica debería demostrar el carácter construido de la naturalización del orden actual y la posibilidad de un orden distinto al existente. Es en este ejercicio de deconstrucción del presente y de revalorización de una agencia volcada a la construcción de otro futuro donde se inserta la alfabetización cívica.

En el fondo, la pedagogía de la posibilidad es un tipo de relación educativa centrada en el desarrollo de la agencia pues es ella la que permite una acción eficaz y soberana para la intervención del entorno biográfico y social. Así, la alfabetización cívica proporciona insumos para la construcción de narrativas contrahegemónicas que soporten una práctica transformadora sobre el mundo. Por este carácter proyectivo, la alfabetización cívica constituye siempre una política de la esperanza (Giroux, 2003).

\section{Profesores intelectuales públicos comprometidos colectivamente}

En el orden educativo neoliberal, el profesor o la profesora son representados como profesionales técnicos que transmiten un conocimiento ya objetivado. Son neutrales (apolíticos) en su ejercicio profesional, 
tanto en los modos como en los contenidos que transmiten. En una pedagogía de las posibilidades, por el contrario, son profundamente políticos, politizados y politizantes. La politicidad es entendida como aquella capacidad de la ciudadanía para deliberar y ejercer plenamente la soberanía sobre sí y sobre el mundo. Un profesorado politizado y politizante es aquel que aprende y enseña la alfabetización cívica, que se posiciona en las disputas actuales y estimula el posicionamiento de los otros, entendiendo que de ello dependen las posibilidades del futuro (Giroux, 1997).

Es en esta relación con el futuro desde donde emerge la exigencia del pensamiento crítico como soporte del ejercicio docente. Este permite enfrentar el carácter problemático del futuro mediante la deliberación de las posibilidades para su construcción colectiva.

El juicio crítico debe dirigirse tanto a los contenidos que se transmiten como a las formas de transmisión. Respecto a los contenidos, el ejercicio docente debe demostrar el carácter selectivo del conocimiento oficial (el ocultamiento que el saber legítimo realiza sobre los saberes vencidos) y estimular la apertura a otros registros epistemológicos o políticos. Respecto a las formas de transmisión (el currículum oculto), la pedagogía de la posibilidad debe establecer una relación de coherencia entre los contenidos y la manera de la transmisión cultural, explicitando el tipo de significaciones, ideologías y relaciones sociales que transmiten en sus ejercicios cotidianos. Así, la reflexión y acción del profesorado deben orientarse a develar el currículum oculto que sostiene sus propias prácticas para hacerlo compatible con el tipo de politicidad deliberado públicamente.

Este ejercicio debe realizarse colectivamente. Lejos de una «agencia neoliberal» que reduce la libertad individual a cuestiones de consumo (la «elección racional»), la «agencia cívica» (propia de la alfabetización cívica) es una agencia pública; es decir, ejerce su soberanía a través de la acción deliberativa comunitaria y orientada por los desafíos colectivos.

En síntesis, por su capacidad crítica, deliberativa y soberana, los profesores no son "técnicos», sino intelectuales, y, en la medida en que su intelectualidad es siempre politizada y politizante, no son agentes individuales transmisores de un saber objetivo, sino actores sociales 
orientados por un tipo de agencia pública y colectiva cuyo horizonte es la apertura de posibilidades para la transformación del futuro.

\section{Educación Superior como esfera pública democrática}

En una pedagogía de la posibilidad, la universidad es tanto un espacio de deliberación cívica como un bien social y un derecho público. Es una institución crítica guiada por la promesa democrática de cultivar la imaginación, la curiosidad, el cuidado, la responsabilidad social y la lucha por la justicia (Giroux, 2016). Sin embargo, dada la prevalencia del mercado en el ordenamiento neoliberal, resulta difícil augurar el fortalecimiento de esta orientación democrática desde la educación.

Ante la ausencia de una perspectiva democrática, no es sorprendente que la Educación Superior abra sus puertas a intereses corporativos, estandarizando el currículum, institucionalizando estructuras de gobierno verticalistas que imitan la cultura empresarial, ignorando los valores sociales o las consecuencias éticas de sus prácticas. Por lo mismo, es cada vez mayor su compromiso con objetivos reproductores; prepara al estudiantado como fuerza laboral precariamente cualificada o a futuros «emprendedores» con un sentido de irresponsabilidad organizada (Giroux et al., 2020).

En este orden de cosas, las principales preguntas que se realizan acerca del conocimiento, el propósito de la educación, la naturaleza de la política y las posibilidades del futuro son definidas por las fuerzas del mercado. Así, la educación se reduce al entrenamiento adaptativo, los valores públicos se transforman en instrumentales y la Educación Superior queda reducida a su performance en sistemas operativos, los mismos que definen la "calidad» a través de mediciones estandarizadas y estimulan la obsesión por la cuantificación y los datos numéricos (Fardella et al., 2021). Esto es una forma de educación corporativizada que carece de cualquier vestigio de visión democrática y revela «la contradicción entre los valores democráticos y el fundamentalismo de mercado» (Guinier y Smith, 2002). Ante 
esto, las universidades están perdiendo su misión pública y su función como sostén de la vida democrática.

A medida que el rol de la universidad como centro de pensamiento crítico y compromiso cívico se devalúan, la sociedad se va transformando en «un espacio espectacular de consumo» y saqueo financiero. Una consecuencia social de esto es la huida permanente de las obligaciones mutuas, de las responsabilidades sociales y la pérdida de fe en la política misma (Giroux, 2016). Esta pérdida de fe en el poder político, el diálogo público y el disenso no está desvinculada de la creciente desconfianza en la Educación Superior como eje central para producir ciudadanas y ciudadanos comprometidos críticamente, alfabetizados cívicamente y con una potente capacidad de agencia. Por ello están en riesgo no solo el sentido de la Educación Superior, sino también la posibilidad de acción de la sociedad civil y aún más, la política y el destino de la democracia misma.

Bajo estas circunstancias, en las instituciones educativas se hace difícil brindar condiciones que potencien las capacidades del estudiantado para pensar críticamente, así como enseñarles a tomar riesgos, a actuar de una manera socialmente responsable y a conectar los temas privados con las consideraciones públicas más generales. El actual ataque neoliberal a la Educación Superior pública, a los sindicatos docentes y al propio estudiantado sugiere que estamos siendo testigos de lo que alguna vez Wright Mills denominó «el colapso de las esferas públicas que ofrecen un sentido de agenciamiento crítico e imaginación social» (Mills, 2008, p. 200). Este es un fenómeno particularmente importante en una sociedad en la que la libre circulación de ideas y el pluralismo están siendo reemplazadas por la homogeneización de "verdades oficiales» difundidas por los medios de comunicación masiva y las redes sociales, y donde las ideas críticas -y en especial, el disenso- son silenciados por un ordenamiento neoliberal que las califica de radicales e incluso sediciosas.

Reclamar la Educación Superior como una esfera pública democrática comienza con el reconocimiento primordial de que la educación no tiene por objetivo la preparación para el trabajo de sujetos «librados» a la gestión de sí mismos y éticamente lisiados, sino la 
formación orientada al compromiso social, el pensamiento crítico, la alfabetización cívica y el desarrollo de la agencia, entendida como la capacidad de acción para otro futuro posible.

\section{Palabras finales}

Como educadores necesitamos reconocer que las formas de la dominación no son solo económicas, sino también culturales, intelectuales y pedagógicas (es decir, una dominación hegemónica). Por ello, cargamos con una enorme responsabilidad ética y política: nuestra acción puede reforzar la reproducción o estimular la transformación del sistema de dominación neoliberal. Tampoco deberíamos perder el valor de la educación como corazón de la política quienes estamos preocupados por invitar a las personas a que regresen a la Educación Superior pública, entendida como un campo de verdadera profundización democrática.

Para enfrentar la devaluación del compromiso educativo democrático, las y los educadores necesitan una pedagogía de ruptura y posibilidad. Es decir, una pedagogía cosmopolita, imaginativa, afirmativa de lo público, que permite conectar los problemas privados con las cuestiones públicas y que promueve una interacción crítica y comprometida con el mundo en que vivimos. El horizonte ético-político de esta pedagogía es desafiar las estructuras de dominación y aliviar el sufrimiento humano. Aproximarse a dicho horizonte requiere de una pedagogía que asume la posibilidad de un futuro distinto a la proyección del orden existente. Y para ello resulta indispensable la enseñanza y el aprendizaje de la agencia cívica. En otras palabras, es una pedagogía que permite afrontar el futuro como un problema colectivo.

Finalmente, si las juventudes deben desarrollar un profundo respeto hacia otros, un marcado sentido de la responsabilidad y una noción instruida de compromiso cívico, la educación debe ser vista como una fuerza cultural, política y moral que brinda el conocimiento, los valores y las relaciones sociales para hacer posibles estas prácticas democráticas entendidas como políticas y praxis de la posibilidad. 


\section{Referencias}

Bernstein, B. (1998). Pedagogía, control simbólico e identidad. Morata.

Bourdieu, P. y Passeron, J. (1995). La reproducción. Elementos para una teoría del sistema de enseñanza. Laia.

De Sousa, B. (2010). Descolonizar el saber, reinventar el poder. TRILCE. Fardella, C., Jiménez, F., Rivera-Vargas, P. y Baleriola, E. (2022). Salir de la sombra. Una revisión sistemática sobre shadowing como propuesta metodológica para la investigación educativa. Revista de Investigación Educativa, 40 (1), 257-174. https://doi.org/10.6018/rie

Freire, P. (1985). Pedagogía del oprimido. Tierra Nueva.

Freire, P. (2012). Pedagogía de la indignación. Cartas pedagógicas en un mundo revuelto. Siglo XXI.

Giroux, H (1997). Los profesores como intelectuales. Hacia una pedagogía critica del aprendizaje. Paidós.

Giroux, H. (2003). Pedagogía y politica de la esperanza. Teoría, cultura y enseñanza. Amorrortu.

Giroux, H. (2004). Teoría y resistencia en educación. Siglo XXI.

Giroux, H. (2016). La Educación Superior y las políticas de ruptura. Entramados: Educación y Sociedad, 3, 15-26.

Giroux, H., Rivera-Vargas, P. y Passeron, E. (2020). Pedagogía pandémica. Reproducción funcional o educación antihegemónica. Revista Internacional de Educación para la Justicia Social, 9 (3), 1-7.

Mills, C. W. (2008). The politics of truth: selected writings of C. Wright Mills. Oxford University Press.

Rivera, P., Neut, S. y Neut, P. (2020). Monográfico: Educación, reproducción y alternativas contrahegemónicas. Revista Izquierdas, 49, 2066-2082. 